\title{
TEMPERATURE-INDUCED CHANGES IN THE CALLS OF THE GREEN LACEWING, \\ CHRYSOPERLA PLORABUNDA (NEUROPTERA: CHRYSOPIDAE)*
}

\author{
By Charles S. Henry \\ The Biological Sciences Group \\ Box U-43, University of Connecticut \\ Storrs, Connecticut 06268
}

Animals communicate acoustically in many different ways and for many different purposes; in fact, a vast literature exists on the subject, and comprehensive efforts to summarize current knowledge have not been attempted since the early 1960's (e.g., Lanyon and Tavolga 1960, Busnel 1963). Insects are especially rich in singing or noise-making species, and it seems likely that every insect order will eventually prove to include acoustically active taxa. Neuroptera has long been regarded as a "silent" order of primitive, behaviorally simple insects. However, recent work suggests that many, if not most, species of the large neuropteran family Chrysopidae are characterized by complex courtship displays accompanied by a specialized form of acoustical signalling (Smith 1922, Toschi 1965, Ickert 1968, Henry 1979 and 1983b). Such lacewing calls or songs are not acoustical in the traditional sense, but instead consist of species-specific substrate-borne vibrations produced by vigorous, stereotyped jerking motions of the insects' abdomens: a phenomenon known as tremulation in other insects (Morris 1980; Henry $1980 \mathrm{a}, \mathrm{c})$, and found also in the ancestral neuropteroid taxon Megaloptera (Rupprecht 1975). Calling behavior is most elaborate in Chrysoperla Steinmann; conspecific males and females of species within that genus cannot mate without first reciprocally exchanging similar or identical vibrational signals in a prolonged courtship duet (Henry 1980b, 1983b). The best studied species in this regard is Chrysoperla plorabunda (Fitch), a common North American form that for some years was considered synonymous with the morphologically identical Eurasian species Ch. carnea (Stephens) (Tjeder 1960, Henry 1983a). Both sexes of this species, when sexually

*Manuscript received by the editor August 2, 1983. 
receptive, produce brief, repetitive volleys of low-frequency abdominal vibration at (approximately) one-second intervals for up to several minutes at a time (Henry 1979, 1980c); in heterosexual duets, the two partners alternately and repeatedly exchange single volleys until copulation is achieved. Each volley in Ch. plorabunda is characterized by a smoothly increasing and then decreasing amplitude envelope and by pronounced frequency modulation (see Fig. 1): the rate of abdominal vibration gradually declines to less than half its initial value during the course of the volley (Henry 1980c).

Green lacewings of the genus Chry'soperla are unusual among acoustical animals in that females are just as likely to sing as males (Henry 1983b). In contrast, males alone (or principally) sing and call conspecific females to them in most species of the best studied animal taxa like birds (Catchpole 1982), lizards (Frankenberg 1982), frogs (Littlejohn 1977), katydids (Dumortier 1963), homopterans (Ossiannilsson 1949, Young 1980), and crickets (Walker 1962, Dumortier 1963). Such unilateral male signalling has been interpreted in most acoustical animals as indicative of sexual selection operating on the higher variance in reproductive success of males (Halliday 1978, Otte 1974, Alexander 1975). On the other hand, the unusual presence of calling behavior in both sexes of Chrysoperla species may stem from the proven importance of their vibrational signals in the reproductive isolation of closely related species. For example, neither of the sibling, interfertile species Ch. plorabunda and Ch. downesi (Banks) will respond to the song of the other, thus precluding courtship duets and preventing interspecific mating under natural conditions (Henry 1983b). If such signals are to be effective as reproductive isolating mechanisms, however, they must remain unambiguous to recipients over the wide range of temperature typically experienced by lacewings in the field. Abundant documentation exists of gross alteration in chirp rate, wing-stroke frequency, pulse or chirp duration, or call notes by temperature changes in many taxonomically disparate insect groups (Brooks 1882, Hayward 1901, Alexander 1956, Walker 1962, Dumortier 1963, Shaw 1968, Booij 1982), and similar temperature-related changes should be characteristic of lacewing songs (see Henry 1982b for preliminary work on Chrysopa oculata Say). One would also predict that the calls of the two sexes of a given species of Chrysoperla should vary in a closely parallel fashion over a wide range of 
temperatures, since mutual recognition of highly specific call features is so important to the reproductive success of both members of each courting pair. Here, I report on the effects of temperature change on the principal parameters of the calls of individual male and female Chri'soperla plorabunda from North America. This paper also contains the first complete description of the frequency structure of the abdominal volleys of that species, together with an experimental analysis of the effects of abdominal mass on frequency characteristics. Regressions of call parameters against temperature in Ch. plorabunda are compared with those described for other singing insects, in an attempt to identify any unifying principles.

\section{Materials And Methods}

A breeding colony of Chrysoperla plorabunda was started in the fall of 1982 from seven males and ten females collected in a field of senescent goldenrod (Solidago spp.) at Storrs, Connecticut. Subsequently, adults were maintained on a Wheast ${ }^{\mathrm{TM}} /$ sucrose diet while larvae were fed ether-killed Drosophila spp. (see Henry 1979, 1983a for details). Males for experimentation were drawn from secondgeneration laboratory stock, while females were third-generation insects; five unmated individuals of each sex were acoustically monitored at various temperatures between $19.5^{\circ} \mathrm{C}$ and $29.8^{\circ} \mathrm{C}$. For each of five call characteristics of interest, I analyzed an average of 40 volleys of abdominal vibration per individual, delivered at three to six different temperatures between the extremes mentioned above; in no case was a regression line for an individual based upon fewer than 18 volleys. Temperature was monitored within $25 \mathrm{~cm}$ of the calling insects, and was controlled by heating and cooling an entire 120 cubic meter room.

Lacewings were induced to call either by playing back to them cassette tape recordings of conspecific signals or by simulating such signals by means of a sweeping audio frequency generator (Tektronix $^{\text {Tm }}$ FG 507) gated by a physiological stimulator (Harvard ${ }^{\mathrm{Tm}}$ 340). Patterns of abdominal vibration were detected and analyzed with techniques and equipment described in other papers (Henry 1980a, 1982b). Details of call parameters were obtained from Polaroid 'm photographs of oscilloscope tracings, using conventional overlay methods.

Several individuals of $C h$. plorabunda from a breeding colony of different geographical origin were selected for use in experiments 
testing the effect of abdominal weight on vibrational frequency. This stock was bred from five males and five females collected in the sagebrush country of southwestern Idaho on 24 May, 1983 by Dr. James Johnson (University of Idaho). I tested one field-caught male, two first-generation laboratory males, and one first-generation laboratory female for the frequency characteristics of their calls at two different temperatures; after ascertaining that all were essentially identical to one another and to Connecticut plorabunda in those characteristics, I weighed each individual to the nearest tenth of a milligram on a Mettler ${ }^{\text {TM }}$ H6T or Sartorius ${ }^{\text {Tm }} 1212$ MP balance and added weight to the middle of their abdomens, using water-based Liquid Paper ${ }^{\text {Tm}}$. Mass-loaded specimens were then reweighed and tested again for the vibrational frequencies of their calls at temperatures in the $25-30^{\circ} \mathrm{C}$ range. All such frequency values were also adjusted to $27^{\circ} \mathrm{C}$ using linear regression C in Fig. 3.

Curve-fitting of paired variables to linear, exponential, or logarithmic functions employed a program designed for a HewlettPackard ${ }^{\text {TM }}$ HP-25 pocket calculator. Any reference in the Results or

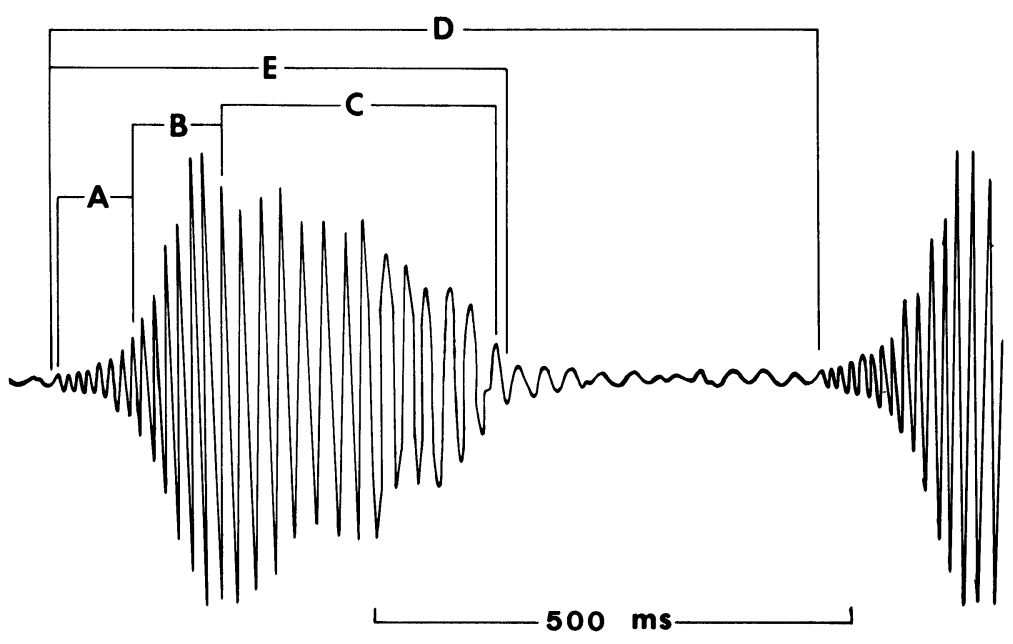

Figure 1. Detailed fragment of the call of Ch. plorabunda, re-drawn from an oscilloscope tracing, showing principal parameters $A-E$ defined in text. $A=$ initial volley frequency, $B=$ median volley frequency, $C=$ terminal volley frequency, $D=$ volley repetition rate, $\mathrm{E}=$ volley duration. 
Discussion sections to "significant differences" indicates that the means of two normally distributed samples were demonstrated to differ from one another by a 2-tailed t-test using confidence limits of $95 \%$ or better. Values following a $+/-$ sign are one standard deviation of the mean.

\section{RESULTS}

I measured five different characteristics of the calls of Chry'soperla plorabunda males and females. These are listed and defined below and illustrated in Fig. 1

A. Initial volley frequency: The cycling rate per second of the first eight strokes of the abdomen, at the start of a volley of abdominal vibration.

B. Median volley frequency: The cycling rate per second of the eight abdominal strokes following the initial period defined above.

C. Terminal volley frequency: The cycling rate per second of the abdominal strokes that remain in a volley after A and B have been deleted.

D. Volley repetition rate: The rate per minute at which a calling lacewing produces volleys of abdominal vibration.

E. Volley duration: The length of time in seconds required for completion of a volley of abdominal vibration.

Frequency of abdominal vibration versus temperature is tabulated for all males and females in Table 1 and expressed as linear regressions for each sex in Figure 2. Since vibration frequency decreases during the course of a plorabunda volley, it is necessary to subdivide each volley into the three portions $\mathrm{A}, \mathrm{B}$, and $\mathrm{C}$, defined above; frequencies measured for those portions are plotted separately on the graph. Other call parameters like volley repetition rate and volley duration are similarly plotted separately for each sex on the same figure, using different units on the y-axis. All data are combined for both sexes in Figure 3, which also displays the range of variation in the calculated regression lines for all 10 individuals.

Several obvious features emerge from these tables and plots. First of all, it appears (Table 1) that males and females differ from each 


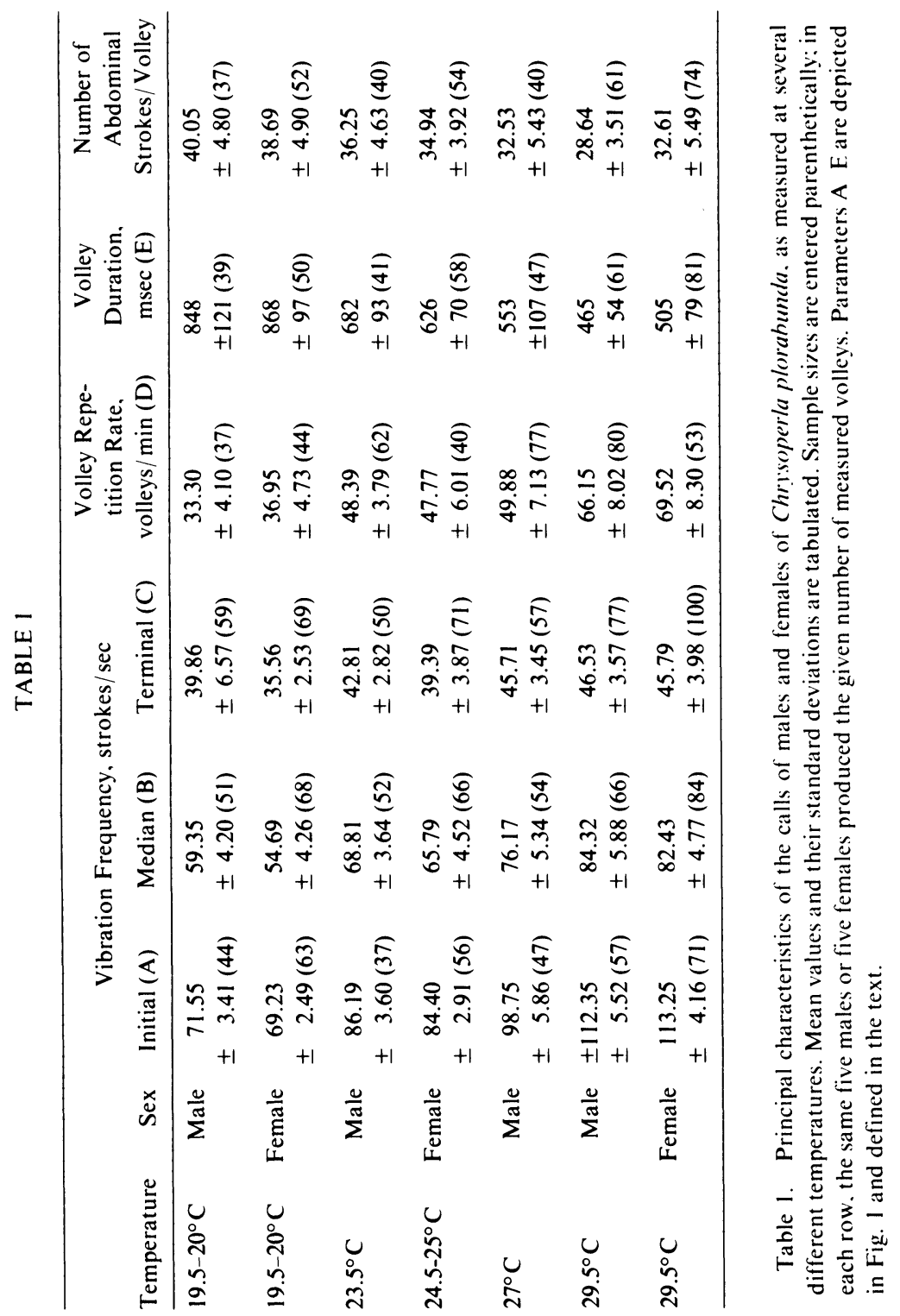


other very little, at any temperature, in any major characteristics of their calls. Particularly coincident between males and females are the initial volley frequencies and the volley durations (Table 1 and Fig. 2A and E) of Ch. plorabunda calls. There is a consistent tendency for females to vibrate their abdomens in later portions of their volleys at somewhat lower frequencies than do males $(35$ cycles $/ \mathrm{sec}$. vs. nearly $40 \mathrm{cps}$ at $20^{\circ} \mathrm{C}$; see Fig. 2C) and for volleys to be produced rather more slowly by males than by females (about 66 volleys/min vs. nearly $70 / \mathrm{min}$ at $29.5^{\circ} \mathrm{C}$; same figure, D), but neither of these differences is statistically significant.

Secondly, it can be seen from Figures 2 and 3 that the slopes for the linear regressions of frequency versus temperature differ radically from one portion of a volley to another, gradually becoming less steep as the volley progresses. Thus, initial portions of volleys change frequency rapidly with temperature (slope $=4.27 x$; Fig. $3 \mathrm{~A}$ ), while terminal portions remain within a much narrower range of values over equivalent temperature extremes (slope $=0.960 \mathrm{x}$ ). Xintercepts also differ significantly for each of the three regressions calculated from pooled frequency data on all ten individuals: intercepts of $3.60,-1.27$, and $-19.09^{\circ} \mathrm{C}$ respectively characterize initial, median, and terminal portions of volleys. Regression of another call parameter, volley repetition rate, against temperature produces a line with a slope of $3.25 \mathrm{x}$ and an $\mathrm{X}$-intercept of $9.14^{\circ} \mathrm{C}$ (Fig. 3D).

Thirdly, Figure 3E demonstrates that volley duration decreases markedly with increasing ambient temperature, and that the mathematical relationship between the two can equally well be interpreted as linear or exponential. In theory, the total number of abdominal strokes per volley could remain constant as temperature varies, since the increased frequency of abdominal vibration at higher temperatures would automatically shorten volley duration. However, data in Table 1 suggest that higher temperatures induce a slight but significant reduction in the total number of abdominal strokes produced during each volley, and that this phenomenon facilitates the volley-shortening process.

Finally, the table and figures all support the view that deviation is relatively slight between the temperature data for each of the various call parameters and the linear regressions calculated from those data. The closest fit to a mathematical relationship is found in the initial frequency of abdominal vibration during a volley: for data 


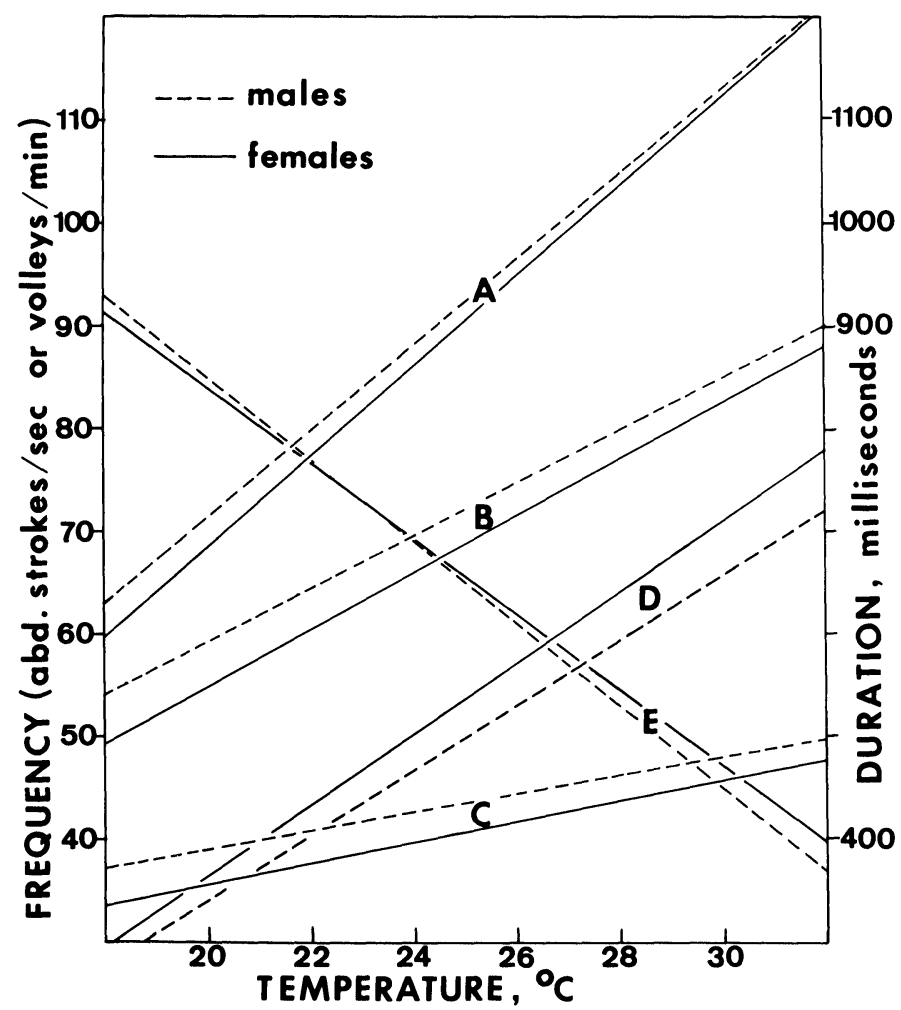

Figure 2. Regression lines, calculated from data in Table 1, showing the effect of temperature on the five principal characteristics A-E of the calls of five males (dashed lines) and five females (solid line) of Ch. plorahunda. The left-hand "frequency" axis applies to parameters $\mathrm{A}-\mathrm{C}$ (strokes/sec) and to $\mathrm{D}$ (volleys/min), while the right-hand axis for "duration" applies only to $\mathrm{E}$.
A. males: $y=4.16 x-11.74, r^{2}=0.96$
females: $\quad y=4.37 x-18.79, r^{2}=0.95$
B. males: $y=2.57 x+7.89, \mathrm{r}^{2}=0.88$
females: $\quad y=2.77 \mathrm{x}-0.55, \mathrm{r}^{2}=0.92$
C. males: $y=0.87 x+21.66, r^{2}=0.69$
females: $\quad y=1.01 x+15.40, r^{2}=0.74$
D, males: $y=3.12 x-27.85, r^{2}=0.81$
females: $y=3.44 x-32.32, r^{2}=0.88$
E. males: $y=-40 x+1650, r^{2}=0.80$
females: $y=-37 x+1580, r^{2}=0.89$ 
pooled from all ten individuals, over 95 percent of variance is explained by regression line A shown in Figure 3. Even for the worst case-terminal volley frequency - nearly two-thirds of raw data variance is compatible with the calculated linear regression $\left(r^{2}=0.65\right)$. And data for individuals are neither more nor less variable, on average, than pooled samples: for the five principal call features graphed in Figure 3, individual $r^{2}$ values average 0.93, 0.84, 0.59, 0.79 and 0.76 and never fall below 0.40 for any single insect. Also shown in that figure is the close congruence of all individual lines for each of the same five call features but particularly for initial volley frequency, suggesting that such temperature relationships are consistent, repeatable, and predictable on an individual basis.

Results of experiments manipulating abdominal mass in individual lacewings are shown in Figure 4 and Table 2. Table 2 presents the raw temperature-frequency data taken from four insects, while Figure 4 shows how those data relate to the linear regressions generated from the terminal volley frequencies of the ten unmodified individuals tested earlier. Converting the frequency measurements to their equivalent values at $27^{\circ} \mathrm{C}$ (Table 2) dramatically reveals how little those data are affected by mass-loading of the abdomen: in none of the four experimental animals was the terminal volley frequency altered significantly by the treatment. Weight increments (from painting) amounted to $10-27 \%$ of total body mass; however, abdominal weights were only $2.8 \mathrm{mg}$ for the female and approximately $2 \mathrm{mg}$ for the three males, so increments to the mass of the vibrating structure itself in each insect actually ranged from 36 to $50 \%$.

\section{Discussion}

The results described above amply document the striking similarity of male and female calls of Chrysoperla plorabunda, consistent with the proven importance of such signalling behavior to the reproductive isolation of this species from several of its morphologically identical siblings in the genus (Henry 1980b, 1983b). Females closely resemble males in every detail of volley structure and spacing, and those few differences that do exist in pooled samples tend to break down when the characteristics of individual insects are compared (Figs. 3 and 4). Also as predicted, males and females 


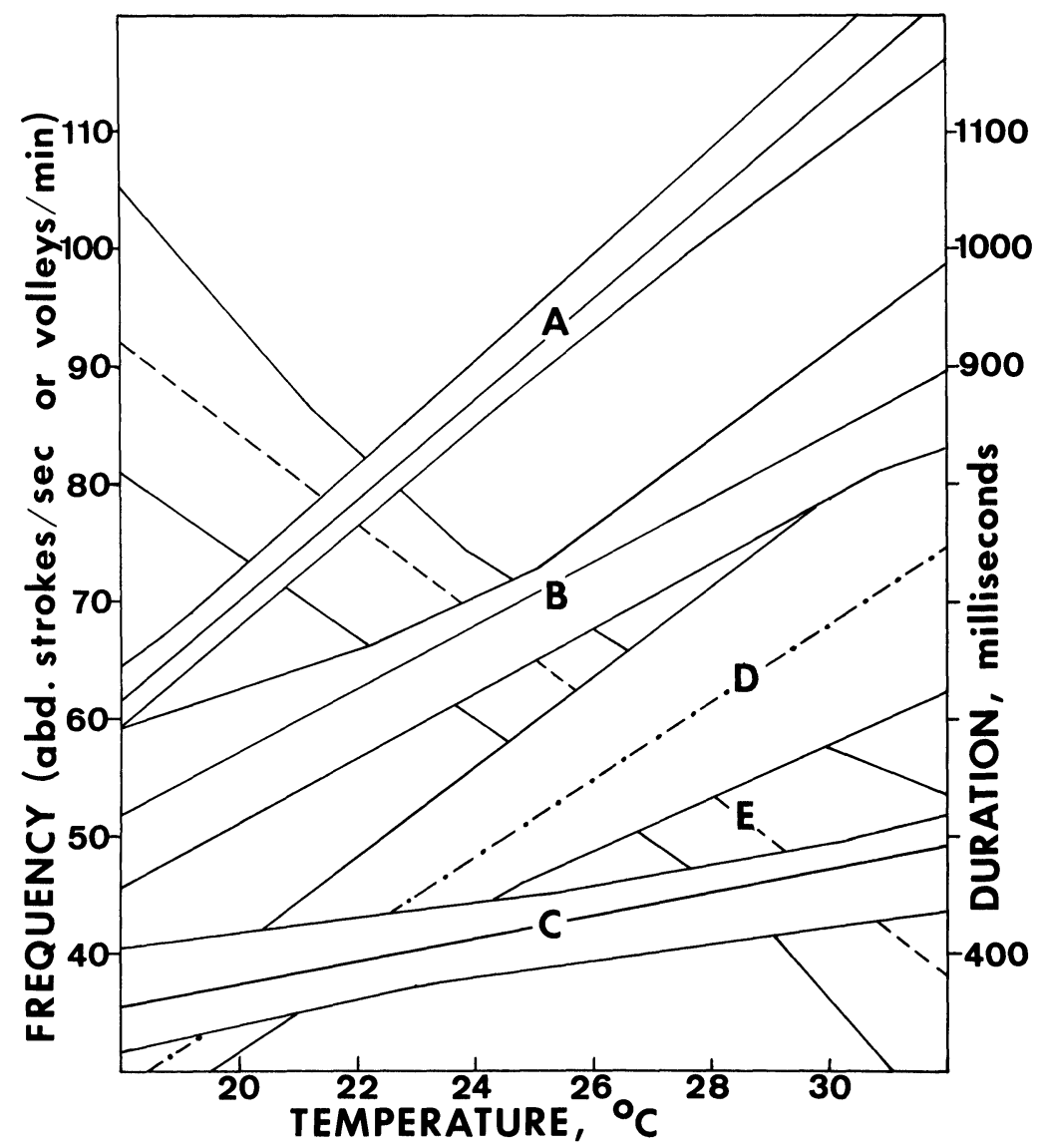

Figure 3. Total range of individual variation of temperature regression lines for the five major call characteristics A-E of Ch. plorabunda. The area above and below each straight line includes within it the linear regresssions for all 10 individuals tested, while the line itself summarizes temperature data for those 10 insects in a single regression equation. Axes and labels as in Fig. 2.
A: $y=4.27 x-15.37, r^{2}=0.95$
B: $y=2.69 x+3.41, r^{2}=0.88$
C: $y=0.96 x+18.33, r^{2}=0.65$
D: $y=3.25 x-29.72, r^{2}=0.83$
$E: y=-39 x+1620, r^{2}=0.83$ 
change their various call characteristics in precisely parallel ways as temperature is altered, so that the sexes' calls remain indistinguishable over the range of temperatures they would typically encounter. The only apparent exception to this conclusion concerns the slightly lower vibration frequencies characteristic of the terminal portions of the volleys of females at all temperatures (Fig. 2C). Such a difference is expected if the terminal volley frequency of a lacewing's abdomen is determined by its inherent capacity to oscillate like a weight on a spring, since the demonstrably heavier abdomen of a female would resonate at a lower frequency than that of a male. However, artificially mass-loading the abdomens of several males and females produced no obvious downward deflections of their frequency characteristics, suggesting that neuro-muscular mechanisms actively "drive" the vibrating system for the entire duration of each volley (Table 2 ) and that resonance effects have relatively little influence on resultant frequencies. Also, as mentioned earlier, the male-female difference in terminal volley frequencies is considerably less impressive when the responses of individual insects are dissected from the pooled data (Fig. 4), thus raising the suspicion that it is an artifact of some sort.

Studies of other acoustical insects overwhelmingly support the existence of linear functions relating temperature to most song parameters that repeat over time, as best exemplified by and documented for rates of wing-stroking, chirping, and "rolling" in cricke is (Alexander 1956, Walker 1962, Dumortier 1963, Prestwich and Walker 1981) and a few katydids and homopterans (Dumortier 1963, Shaw 1968, Whitesell and Walker 1978, Booij 1982). Similarly, most of the temperature data reported here for Ch. plorabunda conform well to linear statistical models, although they are insufficiently detailed to discriminate linear from exponential interpretations. The least individual or pooled variance from the calculated regression is found for the abdominal vibration frequency of the first eight cycles of a volley, suggesting that this feature of the call is particularly crucial to unambiguous communication between the sexes; otherwise, it seems there would exist no need for such precision.

In his 1962 paper on cricket song, Walker drew attention to the apparent convergence of many of his linear regressions on $4^{\circ} \mathrm{C}$; that is, it seemed that for many different cricket species the chirp 
Table 2. Effect on terminal volley frequency (C), in abdominal strokes/sec, of artificially mass-loading the abdomen of three males and one female of $\mathrm{Ch}$. plorabunda. Weight gains are tabulated in column 3: the last column lists $\mathrm{n}$, the number of volleys measured. Equivalent frequencies (at $27^{\circ} \mathrm{C}$ ) in column six were calculated from the slope of regression line $C$ in Fig. 3. Superscript " $x$ " denotes lab-reared insects.

\begin{tabular}{|c|c|c|c|c|c|c|}
\hline & & $\begin{array}{c}\text { Weight. } \\
\text { mg. }\end{array}$ & $\begin{array}{l}\text { Temp.. } \\
{ }^{\circ} \mathrm{C} .\end{array}$ & $\begin{array}{c}\text { Vibration } \\
\text { frequency, } \pm \mathrm{SD}\end{array}$ & $\begin{array}{l}\text { Equivalent } \\
\text { at } 27^{\circ} \mathrm{C} \text {. }\end{array}$ & $\mathrm{n}$ \\
\hline Male 1 & $\begin{array}{r}\text { control } \\
\text { mass-loaded }\end{array}$ & $\begin{array}{l}7.5 \\
9.0\end{array}$ & $\begin{array}{l}26.8 \\
30.0\end{array}$ & $\begin{array}{l}39.78 \pm 1.83 \\
47.08 \pm 1.84\end{array}$ & $\begin{array}{l}39.98 \\
44.00\end{array}$ & $\begin{array}{l}29 \\
20\end{array}$ \\
\hline Male $1^{x}$ & $\begin{array}{r}\text { control } \\
\text { mass-loaded }\end{array}$ & $\begin{array}{l}6.7 \\
8.5\end{array}$ & $\begin{array}{l}27.1 \\
27.0\end{array}$ & $\begin{array}{l}44.49 \pm 2.44 \\
44.59 \pm 3.52\end{array}$ & $\begin{array}{l}44.51 \\
44.59\end{array}$ & $\begin{array}{l}20 \\
25\end{array}$ \\
\hline Male $2^{x}$ & $\begin{array}{r}\text { control } \\
\text { mass-loaded }\end{array}$ & $\begin{array}{l}7.2 \\
8.5\end{array}$ & $\begin{array}{l}27.3 \\
26.8\end{array}$ & $\begin{array}{l}45.98 \pm 2.44 \\
44.92 \pm 2.80\end{array}$ & $\begin{array}{l}45.60 \\
45.15\end{array}$ & $\begin{array}{l}36 \\
36\end{array}$ \\
\hline Female $1^{x}$ & $\begin{array}{r}\text { control } \\
\text { mass-loaded }\end{array}$ & $\begin{array}{c}9.6 \\
10.6\end{array}$ & $\begin{array}{l}27.3 \\
27.0\end{array}$ & $\begin{array}{l}43.47 \pm 2.31 \\
43.14 \pm 2.50\end{array}$ & $\begin{array}{l}43.20 \\
43.14\end{array}$ & $\begin{array}{l}28 \\
19\end{array}$ \\
\hline
\end{tabular}

and pulse (=wing stroke) rates went to zero at about $4^{\circ} \mathrm{C}$ when their temperature regressions were extrapolated downward. The same phenomenon can be seen in other insects, as well, including several tettigoniids studied or reported by Dumortier (1963), Shaw (1968), and Whitesell and Walker (1978) and two delphacid homopterans studied by Booij (1982). Temperature data for initial volley frequency and volley repetition rate of lacewing calls are also reasonably consistent with the concept of regression convergence, since the $\mathrm{x}$-intercepts for relevant call parameters range from $2.82^{\circ} \mathrm{C}$ to $9.40^{\circ} \mathrm{C}$ in $\mathrm{Ch}$. plorabunda and average $8.31^{\circ} \mathrm{C}$ in Chrysopa oculata (Henry 1982b). However, the flatter slopes of the temperaturefrequency regressions for middle and terminal portions of plorabunda volleys cause those lines to intersect the $\mathrm{x}$-axis at $-1.27^{\circ} \mathrm{C}$ and $-19.09^{\circ} \mathrm{C}$, respectively, which does not fit well with Walker's generalization. Moreover, other examples from the literature fail to confirm the phenomenon, even in certain crickets and katydids recently studied by Walker himself (and collaborators): for instance, Anurogry'lus arboreus and winter races of Neoconocephalus triops both display rather flat regression lines of temperature versus wing stroke rate that intersect the $\mathrm{x}$-axis well below $-5^{\circ} \mathrm{C}$ (Prestwich and Walker 1981, Whitesell and Walker 1978). Thus, Walker's "four 


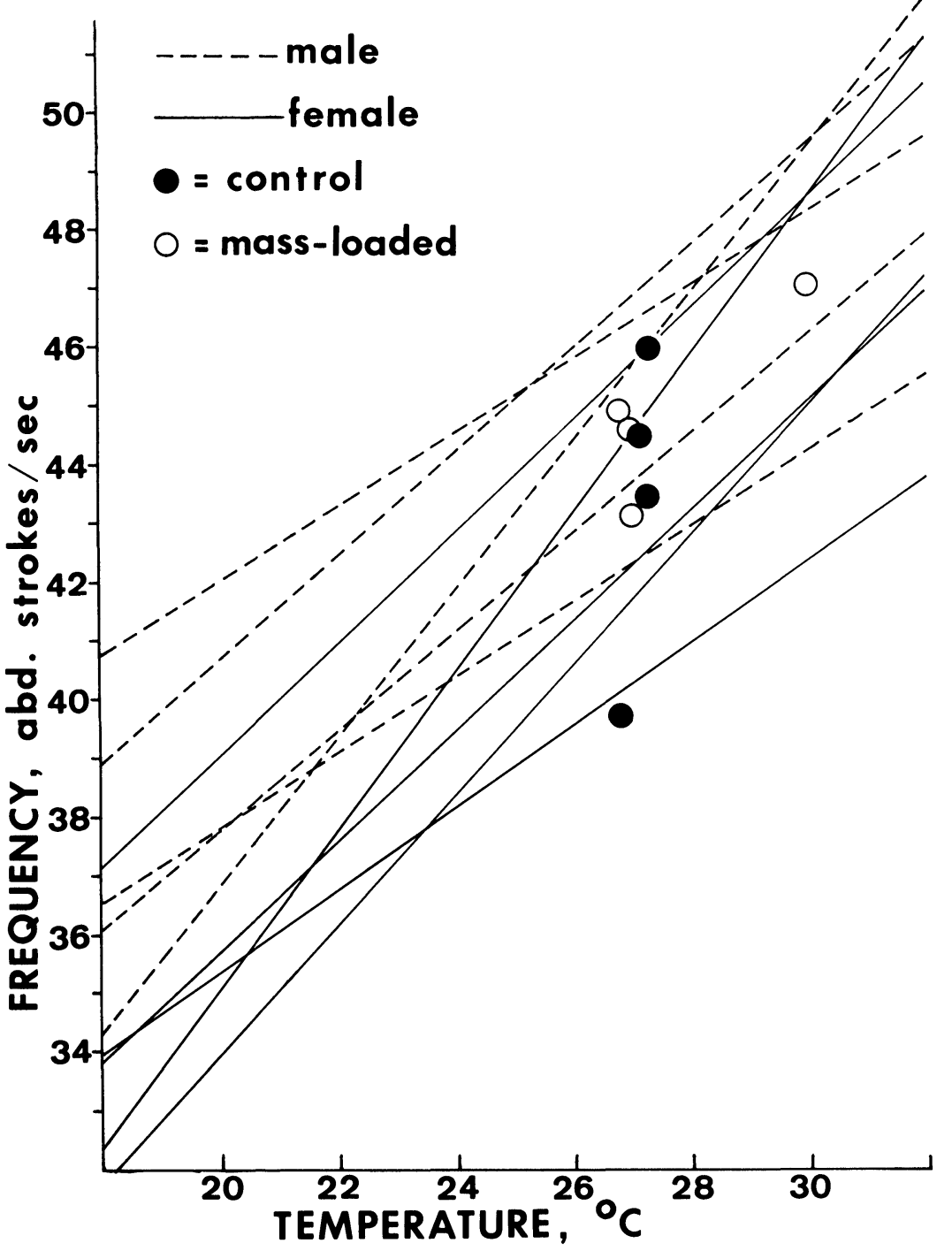

Figure 4. Effect on terminal volley frequency (C) of artificially mass-loading the abdomen of four Ch. plorabunda individuals, superimposed on a graph showing the calculated temperature regression lines of terminal volley frequency for 10 other insects of the same species. 
degree rule" is intriguing but far from universal and applies only partially to the lacewing calls described here; why the rule should apply at all, to any insect call parameter, is still unknown.

It should not be assumed from the discussion above that linear regressions characterize the temperature relationships of all insect song parameters. In fact, it is likely that all temperature regressions are ultimately exponential in form when based upon data taken over a sufficiently wide temperature range, since the kinetics of the physiochemical processes underlying song production are non-linear with respect to temperature. One conspicuous example is the pulse (or chirp) duration of the French tettigoniid Ephippiger provincialis (Yers.), which varies inversely with temperature in a "hyperbolic" manner (Dumortier 1963, fig. 229). The volley duration typical of calling Ch. plorabunda also decreases with temperature (Fig. 3E), but the function describing that decrease seems more linear than hyperbolic or logarithmic over the chosen range of temperatures, and the slope of the relationship is twice as steep as that shown for the tettigoniid. Unless thermoregulation by the larger-bodied katydids accounts for these differences, one can conclude only that distinct physiological mechanisms determine pulse, chirp, or volley durations in different insect groups.

Recently, Michelson et al. (1982) published a comprehensive theoretical and empirical study treating general aspects of the physics, transmissibility, and energetics of the vibrational songs of insects. This study provides a rationale for the observed frequency modulation of Ch. plorabunda volleys, and by implication helps to explain why lacewing singers strictly control the frequencies of all portions of their volleys, rather than simply allowing their abdomens to oscillate at their frequencies of resonance. Viewing the plant substrates of vibrating or tremulating insects as acoustical filters, Michelson et al. concluded that signals consisting of multiple frequencies should propagate more uniformly (and effectively) through their substrates than narrow-bandwidth calls, since a signal of relatively pure tone tends to excite a certain pattern of standing waves in its substrate and will therefore vary tremendously in its intensity from place to place on that substrate. Broad-bandwidth or frequencymodulated signals, on the other hand, are ideally suited for penetrating such acoustical filters, so that at least a portion of the call's energy reaches the receptors of the recipient individual or partner. Although the authors reported frequency changes on the order of 
$30-40 \%$ in the calls of their bugs and small cicadas, lacewings of the species Ch. plorabunda alter their rate of abdominal vibration by $50-60 \%$ during each volley, suggesting that their calls can propagate efficiently and evenly through a variety of substrate types. However, if all this is true, it remains to be explained why other lacewing species like Ch. downesi and Ch. carnea (central Europe) produce long calls of nearly constant frequency characteristics (Henry 1980b, 1983a). Perhaps specific properties of the typical substrates utilized by those species have shaped and narrowed the frequency ranges of their calls over evolutionary time: for example, Ch. downesi may be responding to some inherent acoustical property of conifer needles, since its ecological niche is restricted to the evergreen forests of North America.

\section{Summary}

This study assesses the effects of temperature on the major characteristics of the vibrational song of a North American green lacewing, Chrysoperla plorabunda (formerly Ch. carnea). Those parameters include the volley repetition rate, the average duration of volleys, the total number of abdominal strokes per volley, and the vibrational frequency structure of volleys. In general, temperature affects the call in a direct linear manner, so that linear regression equations (of differing slopes) can be used with confidence to describe the relationship between temperature and each measurable trait of a lacewing's song. Additionally, variation in these equations among individuals or between the sexes is negligible, so all members of the species produce calls of remarkably similar construction at all reasonable ambient temperatures-a prerequisite to unambiguous communication among conspecifics. That the weight of an individual's abdomen has no effect on the frequency characteristics of its call was demonstrated experimentally by mass-loading the abdomens of several sexually receptive insects. The relevance of these findings to the biological function of lacewing calling, as well as to the physics of substrate-borne vibrations, is discussed briefly.

\section{ACKNOWLEDGMENTS}

This study was supported in part by National Science Foundation award \#DEB-79-11537 to the author. I thank Dr. James Johnson, University of Idaho (Moscow), for sending me living Chrysoperla 
plorabunda from his home state. Drs. Theodore Taigen and Stephen Pacala (University of Connecticut) provided useful suggestions throughout the study, while Ms. Burma Stelmak generously typed and edited the manuscript. Ms. Jane O'Donnell (University of Connecticut Museum of Natural History) read and constructively criticized an early draft of the paper.

\section{L.ITherat're: Cited}

Alexander, R. D.

1956. A comparative study of sound production in insects, with special reference to the singing Orthoptera and Cicadidae of the eastern United States. Ph.D dissertation. Ohio State University. 529 pp.

1975. Natural selection and specialized chorusing behavior in acoustical insects. In Pimental, D.. ed.. Insects, Science and Sociely, pp. 35-77. Academic Press, N.Y.

BoOIJ, C. J. H.

1982. Biosystematics of the Muellerianella complex (Homoptera, Delphacidae), interspecific and geographic variation in acoustic behavior. $\mathbf{Z}$. Tierpsychol. 58: $31-52$.

BROOKS, M. W.

1882. Influences of temperature on the chirp of the cricket. Popular Sci. Month. 20: 268.

Busnel, R. G.

1963. Acoustic Behavior of Animals. Elsevier Publ. Co., N.Y., 933 pp.

CatchPol.e, C. K.

1982. The evolution of bird sounds in relation to mating and spacing behavior. In Kroodsma, D. E., and E. H. Miller, eds., Acoustic Communication in Birds, Vol. 1. pp. 297-319. Academic Press, N.Y.

DIMORTIER, B.

1963. The physical characteristics of sound emissions in Arthropoda. In Busnel, R. G.. ed., Acoustic Behavior of Animals, pp. 346-373. Elsevier Publ. Co.. N.Y.

Frankenherg E.

1982. Vocal behavior of the Mediterranean house gecko Hemidactylus turci('us. Copeia 1982(4): 770-775.

HaLLIDAY, T. R.

1978. Sexual selection and mate choice. In Krebs, J. R., and N. B. Davies, eds., Behavioural Ecologl', pp. 180-213. Blackwell Sci. Publs., Oxford.

HaYWARD, R.

1901. The katydid's call in relation to temperature. Psyche 9: 179.

Henty, C. S.

1979. Acoustical communcation during courtship and mating in the green lacewing Chrisopa carnea (Neuroptera: Chrysopidae). Ann. Entomol. Soc. Am. 72(1): 68-79. 
1980a. Acoustical communication in Chrisopa rufilabris (Neuroptera: Chrysopidae), a green lacewing with two distinct calls. Proc. Entomol. Soc. Wash. 82(1): 1-8.

1980b. The courtship call of Chrysopa downesi Banks (Neuroptera: Chrysopidae): its evolutionary significance. Psyche 86(2-3): 291-297.

1980c. The importance of low-frequency, substrate-borne sounds in lacewing communication (Neuroptera: Chrysopidae). Ann. Entomol. Soc. Am. 73(6): 617-621.

1982a. Reply to Tauber and Tauber's "Sympatric Speciation in Chrysopa: further discussion." Ann. Entomol. Soc. Am. 75: 3-4.

1982b. Reproductive and calling behavior in two closely related, sympatric lacewing species, Chrisopa oculata and C. chi (Neuroptera: Chrysopidae). Proc. Entomol. Soc. Wash. 84: 191-203.

1983a. Acoustic recognition of sibling species within the holarctic lacewing Chrysoperla carnea (Neuroptera: Chrysopidae). Systematic Entomol. 8: 293-301.

1983b. (in press). Sexual behavior of green lacewings. In Séméria, Y., and T. R. New, eds., Biology' of Chrisopidae. Junk Publishers, Netherlands.

ICKERT, G.

1968. Beiträge 7ur Biologie einheimischer Chrysopiden (Planipennia, Chrysopidae). Entomol. Abh. Dresden 36: 123-192.

LANYON, W. E., AND W. N. Tavol.ga.

1960. Animal Sounds and Communication. Publ., \#7, AIBS, Washington, D.C. $443 \mathrm{pp}$.

LitTi.eJOHN, M.

1977. Long-range acoustic communication in anurans: an integrated and evolutionary approach. In Taylor, D. H., and S. I. Guttman, eds., The Reproductive Biology of Amphibians, pp. 263-294. Plenum Press, N.Y.

Miculi.sen, A., F. Fink, M. Gogal.A, and D. Traue.

1982. Plants as transmission channels for insect vibrational songs. Behav: Ecol. Sociobiol. 11: 269-281.

Morris, G. K.

1980. Calling display and mating behavior of Copiphora rhinoceros Pictet (Orthoptera: Tettigoniidae). Anim. Behav. 28: 42-51.

OssiaAnil.sson, F.

1949. Insect drummers. Opusc. Entomol. Suppl. X: 1-145.

OTTE, D.

1974. Effects and functions in the evolution of signaling systems. Ann. Rev. Ecol. Syst. 5: 385-417.

Prestwich, K. N. and T. J. Wal.ker.

1981. Energetics of singing in crickets: effect of temperature in three trilling species (Orthoptera: Gryllidae). J. Comp. Physiol. 143: 199-212.

RUPPRECHT, R.

1975. Die Kommunikation von Sialis (Megaloptera) durch Vibrationssignale. J. Ins. Physiol. 21: 305-320. 
Shaw, K. S.

1968. An analysis of the phonoresponse of males of the true katydid, Pterophilla camellifolia (Fabr.) (Orthoptera: Tettigoniidae). Behaviour 31: 203-259.

SмIтн, R. C.

1922. The biology of the Chrysopidae. Cornell University Agric. Expt. Stn. Mem. 58: 1291-1372.

TJEDER, B.

1960. Neuroptera from Newfoundland, Miquelon, and Labrador. Opusc. Entomol. 25: 146-149.

Toschi, C. A.

1965. The taxonomy, life histories, and mating behavior of the green lacewings of Strawberry Canyon. Hilgardia 36: 391-431.

WALKER, T. J.

1962. Factors responsible for intraspecific variation in the calling songs of crickets. Evolution 16: 407-428.

Whitesel., J. J. AND T. J. WALKER.

1978. Photoperiodically determined dimorphic calling songs in a katydid. Nature 274(5674): 887-888.

Young, D.

1980. The calling song of the bladder cicada, Cystosoma saundersii: a computer analysis. J. Exp. Biol. 88: 407-411. 

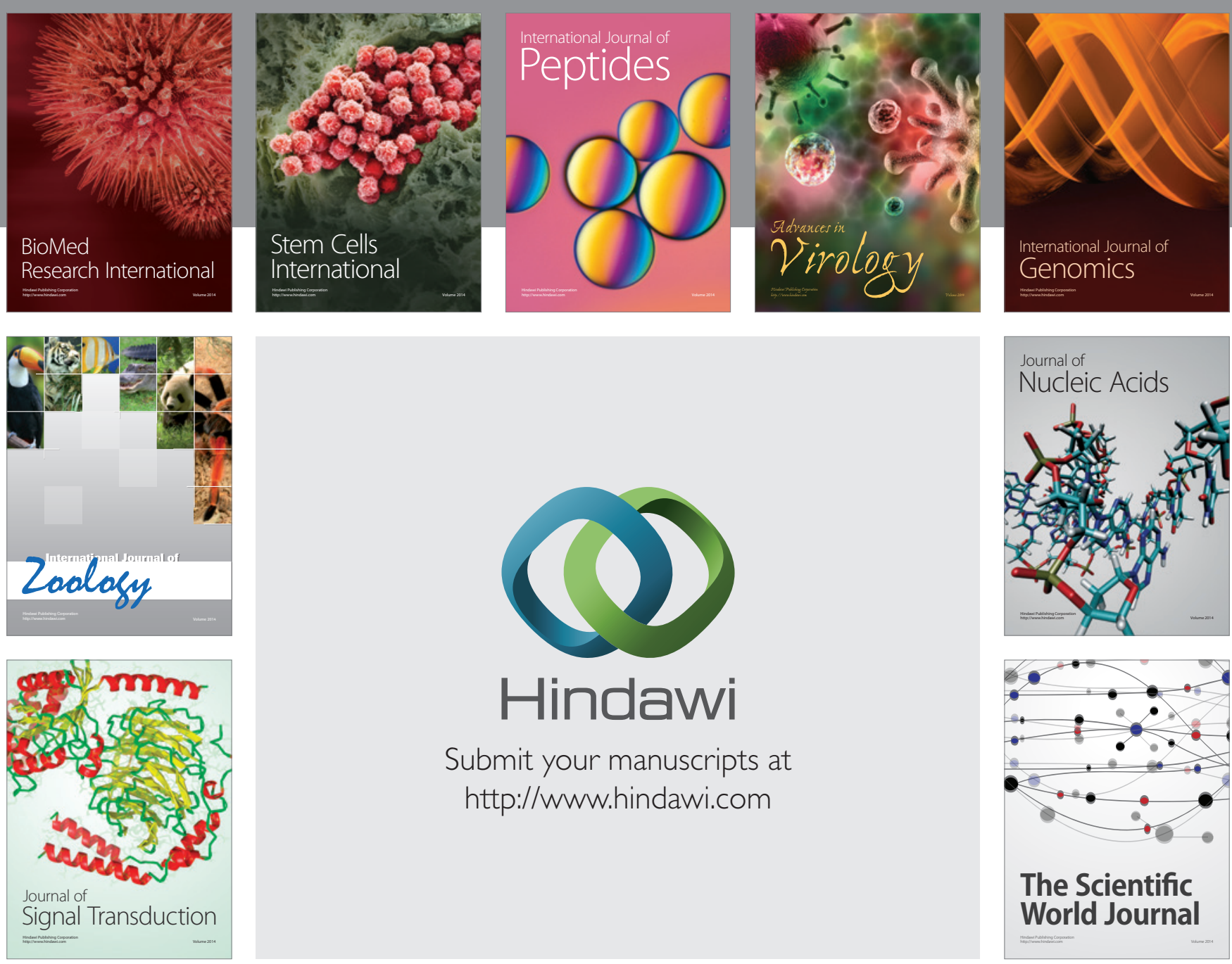

Submit your manuscripts at

http://www.hindawi.com
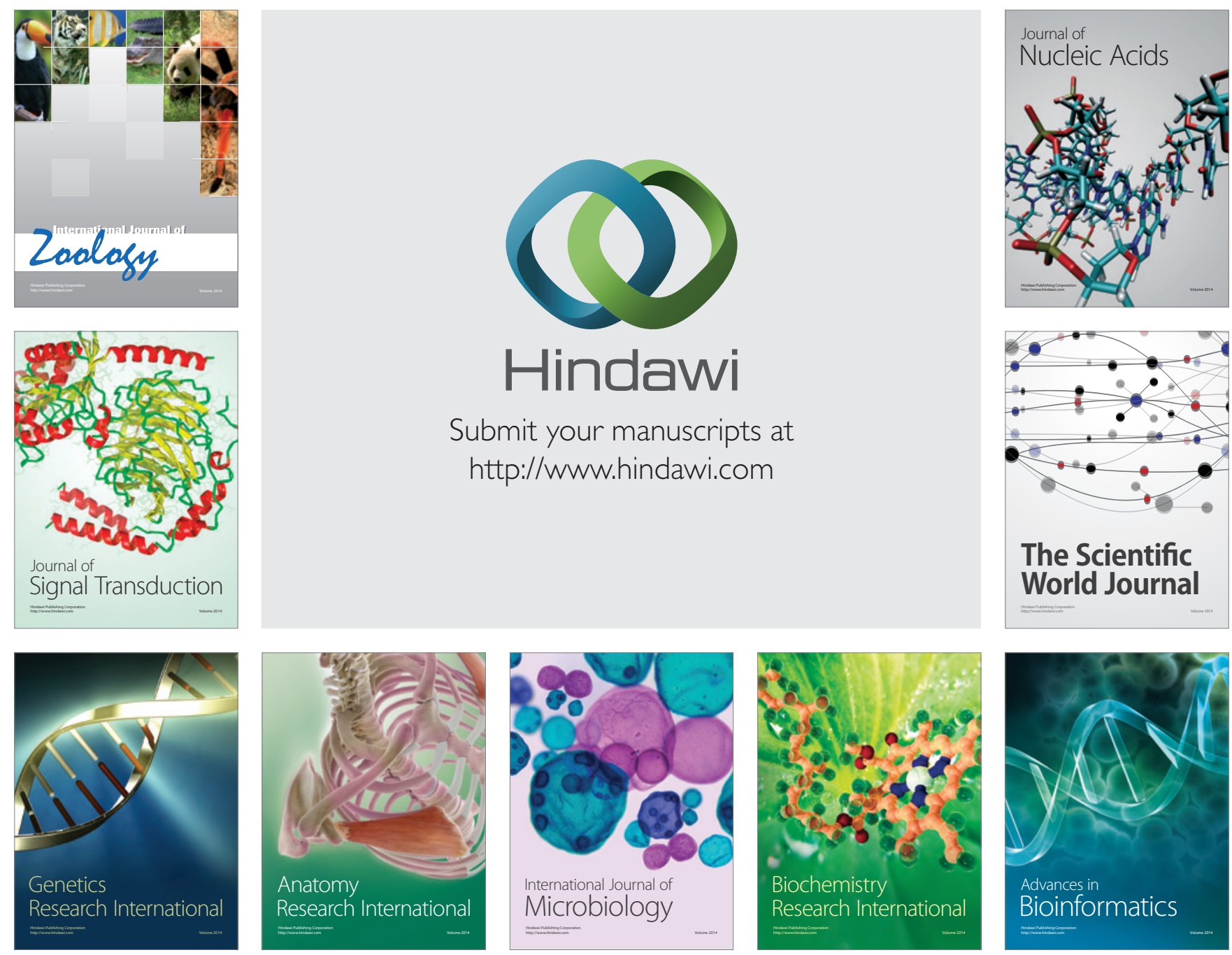

The Scientific World Journal
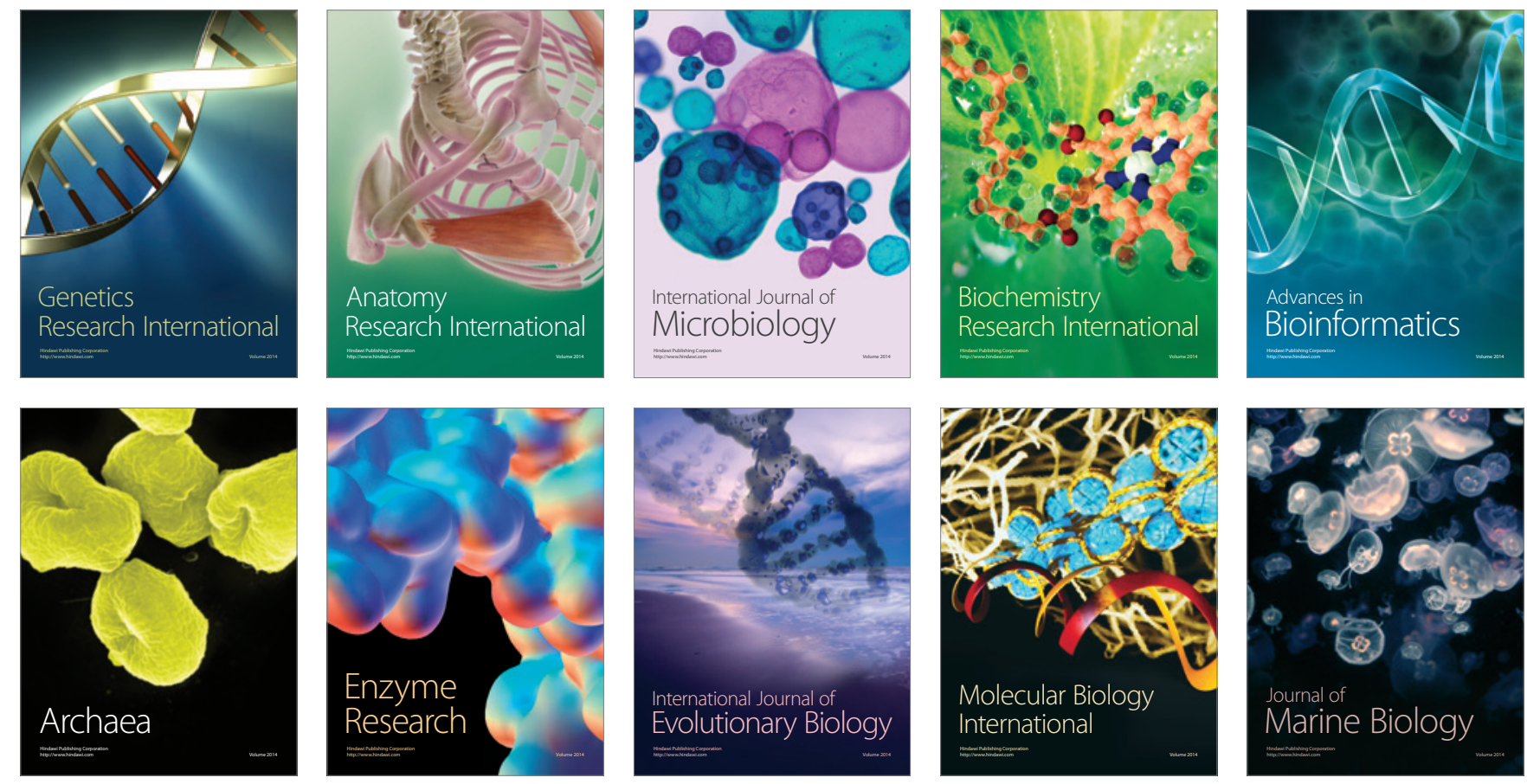